\title{
PSEUDARTHROSIS OF THE SCAPHOID IN IMMATURE SKELETONS
}

Marcelo Barreto de Lemos ${ }^{1}$, Ádria Simone Ferreira Bentes ${ }^{2}$, Miguel Flores do Amaral Neto ${ }^{3}$, Leandro de Freitas Spinelli ${ }^{4}$, Antônio Lourenço Severo ${ }^{5}$, Osvandré Lech ${ }^{6}$

\section{ABSTRACT}

This paper presents a review of the literature on pseudarthrosis of the scaphoid in skeletally immature individuals, taking into consideration its epidemiology, diagnosis and treatment, as well as its controversies. Knowledge of this subject makes it possible for patients to be given appropriate treatment immediately. Pseudarthrosis of the scaphoid in skeletally immature patients is a rare condition that results from error or lack of diagnosis of a fracture. Thus, careful clinical and radiographic examination should be performed in order to confirm or rule out this diagnosis. Several treatment methods have been reported and have shown good results. These include conservative plaster cast treatment, bone graft without osteosynthesis, bone graft with Kirschner wires, percutaneous screws and bone graft with compression screws. The treatment performed depends on the characteristics of the pseudarthrosis and the surgeon's experience.

Keywords - Pseudarthrosis; Scaphoid Bone; Wrist; Wounds and Injuries

\section{INTRODUCTION}

Pseudarthrosis of the scaphoid in immature skeletons has been described by some authors, but because of the rarity of this lesion, diagnostic suspicion is rarely aroused and there is some controversy regarding its treatment ${ }^{(1)}$. Identifying the lesion is made difficult because of lack of or error in diagnosing scaphoid fractures. This may occur because of the radiological difficulties inherent to immature skeletons and because of the usual tendency to observe only the distal extremity of the radius, where trauma occurs much more frequently ${ }^{(1-3)}$.

Fractures of the scaphoid in children are rare and represent $0.4 \%$ of fractures of the upper limbs and $2.9 \%$ of fractures of the wrist and hand. The low incidence in children is probably due to the thickness of the cartilage that covers and protects the center of ossification, such that considerable energy is needed for fracturing to occur. Unlike what occurs in adults, fractures of the scaphoid in children affect the distal pole in 59 to $87 \%$, the middle portion in 12 to $36 \%$ and the proximal pole in 0 to $2 \%$. Children also present a very low rate of pseudarthrosis $(0.8 \%)^{(1,2,4-6)}$.

Taleisnik and Kelly ${ }^{(7)}$ reported that the vascular supply of the scaphoid does not change with growth. Both in adults and in children, the proximal pole of the scaphoid has a poor vascular supply because of retrograde intraosseous blood flow, thus making occurrences of pseudarthrosis possible ${ }^{(3,7)}$.

The natural history of pseudarthrosis of the scaphoid in immature skeletons is unknown. The biomechanical alterations seen in the wrists of adults have not yet been reported in children ${ }^{(8-10)}$. A differential diagnosis need to be made with bipartite scaphoid, which is usually bilateral, asymptomatic and unrelated to previous trauma. The two halves of a bipartite scaphoid are radiologically separate, with similar densities and regular borders ${ }^{(2,3)}$.

1 - Instructor Physician for Medical Residence and the Hand Surgery Service, Institute of Orthopedics and Traumatology, Passo Fundo, RS, Brazil.

2 - Fellow in Hand Surgery, Institute of Orthopedics and Traumatology, Passo Fundo, RS, Brazil.

3 - Resident Physician at the Institute of Orthopedics and Traumatology, Passo Fundo, RS, Brazil.

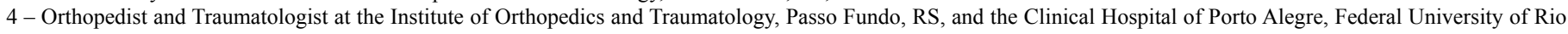
Grande do Sul, Porto Alegre, RS, Brazil.

5 - Instructor Physician for Medical Residence and the Hand Surgery Service, Institute of Orthopedics and Traumatology, Passo Fundo, RS, Brazil.

6 - Head of the Medical Residence Service and the Hand Surgery Service, Institute of Orthopedics and Traumatology, Passo Fundo, RS, Brazil.

Work performed at the Institute of Orthopedics and Traumatology, Passo Fundo, RS, Brazil.

Correspondence: IOT, Rua Uruguai 2050, Centro, 99010-150 Passo Fundo, RS, Brazil. E-mail: mblemos@terra.com.br; ensino@iotrs.com.br

Work received for publication: October 10, 2011; accepted for publication: October 10,2011.

The authors declare that there was no conflict of interest in conducting this work 
Louis et al ${ }^{(11)}$ studied 196 human fetuses and reviewed 11,280 radiographs of children's hands, and did not find any examples of bipartite scaphoid. From this, they concluded that this condition is acquired through trauma, which results in asymptomatic pseudarthrosis of the scaphoid.

In cases of late presentation or negligence at the time of the injury (with continuing mobility at the focus of the fracture), there is the possibility that pseudarthrosis might occur. When such diagnoses are made, patients need to receive the appropriate treatment.

\section{Classification}

Pseudarthrosis of immature skeletons is classified by most authors into four types, as prescribed by Filan and Herbert ${ }^{(12)}$ : D1 - fibrous union; D2 - pseudarthrosis; D3 - sclerotic pseudarthrosis; D4 - avascular necrosis. This classification provides a guide for surgeons regarding the type of treatment to use ${ }^{(1,8,9,12)}$ (Figure 1).

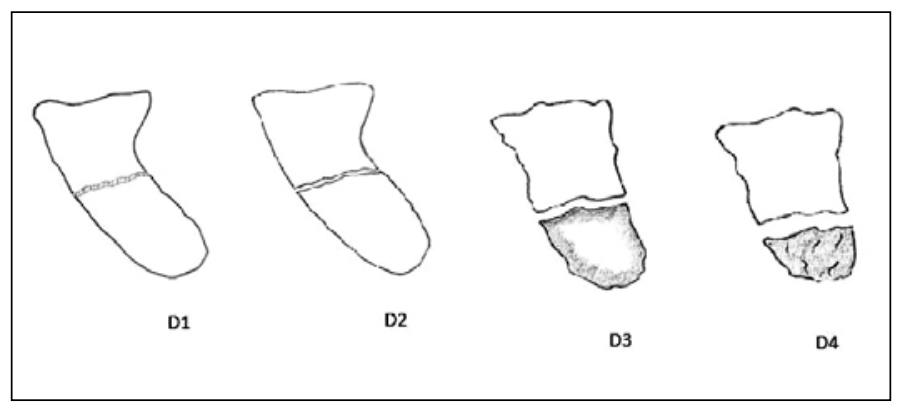

Figure 1 - Filan and Herbert classification ${ }^{(12)}$.

\section{Clinical condition}

The clinical condition varies from asymptomatic states to presence of symptoms like persistent pain and edema. Physical examinations on symptomatic cases show that the anatomical snuffbox is sensitive to palpation and that wrist mobility is limited. Most cases present previous histories of trauma ${ }^{(1,10,13,14)}$.

\section{Diagnosis through imaging}

Radiographs in anteroposterior and lateral views are fundamental in making the diagnosis. They may also be complemented by specific views for the scaphoid ${ }^{(8,9,13)}$. Masquijo and Willis ${ }^{(1)}$ reported that the presence of sclerosis, cystic formations and bone reabsorption define pseudarthrosis on radiographic images. On the other hand, Osterman and Mikulics ${ }^{(15)}$ defined pseudarthrosis of the scaphoid as a situation in which consolidation had not occurred three months after the injury.

Initial negative radiographs at the time of the fractu- re of the scaphoid in children were reported by Evenski et $\mathrm{al}^{(5)}$, thus showing that $30 \%$ of their patients did not present any initial radiographic evidence of a fracture, although there was a high level of clinical suspicion. These patients presented positive radiographs over the course of the follow-up. These authors thus recommended that physicians should be more attentive to patients who presented pain on palpating the scaphoid and on mobilizing the wrist. In such cases, the patient should be immobilized for two weeks and the examination should then be repeated, with new radiographs.

Clarke et $\mathrm{al}^{(13)}$ highlighted the importance of adequate orthopedic follow-up and radiological examinations for children with suspected fractures of the scaphoid, so as to prevent progressive arthritis and future surgical treatment for pseudarthrosis of the scaphoid.

Computed tomography assists in viewing the shape and angles of the scaphoid, and magnetic resonance imaging (MRI) helps in detecting necrosis of the proximal pole of the scaphoid. Johnson et $\mathrm{al}^{(16)}$ reported that MRI is as sensitive among children as it is among adults for detecting wrist injuries.

\section{Treatment and controversies}

Most fractures of the scaphoid in immature skeletons respond well to conservative treatment using a plaster cast. Several authors have suggested that short plaster casts should be used among children for six to eight weeks and among adolescents for eight to twelve weeks. However, displaced fractures require surgical treatment in order to avoid skewed consolidation or pseudarthrosis ${ }^{(2,6,17)}$.

The treatment for pseudarthrosis of the scaphoid in adults is well established. However, for children, there is still some controversy regarding the best protocol to follow $^{(2)}$. Several methods have been reported to present good results, including conservative treatment with plaster casts, bone grafts without osteosynthesis, bone grafts with Kirschner wires, percutaneous screws and bone grafts in association with compression screws ${ }^{(1,4)}$.

Weber et $\mathrm{al}^{(18)}$ proposed prolonged treatment with plaster-cast immobilization for pseudarthrosis of the scaphoid in the cases of six children, for a mean period of five months (i.e. until consolidation was attained). They reported that no stiffness or osteoporosis was seen in their cases and that full wrist mobility was achieved. Chloros et $\mathrm{l}^{(10)}$ and Duteille et $\mathrm{al}^{(19)}$ did not agree with the use of a plaster cast for a prolonged period because in their view, it might not provide the 
solution for the potential problems of pseudarthrosis of the scaphoid (shortening of the scaphoid), which could potentially cause degenerative conditions of the wrist. Suzuki and Herbert ${ }^{(20)}$ reported on two cases of spontaneous correction of the scaphoid after pseudarthrosis, over a four-year follow-up period, without corrective osteotomy or bone grafting. Fabre et al ${ }^{(21)}$ recommended that the initial treatment should be with a plaster cast, and that if there was no clinical or radiological improvement after three months, surgical treatment would become the best option.

Pick and Segal ${ }^{(22)}$ described a case of fracture of the scaphoid in an eight-year-old child who, despite adequate immobilization, evolved to non-consolidation. However, the lesion became completely asymptomatic without any type of treatment. Radiologically, pseudarthrosis of the scaphoid takes the form of a bipartite scaphoid. Furthermore, Clarke et al ${ }^{(13)}$ reported the case of an 11-year-old child who achieved spontaneous consolidation of the scaphoid two years after the fracture, without any type of treatment.

Henderson and Letts ${ }^{(23)}$ evaluated 20 cases of pseudarthrosis of the scaphoid in immature skeletons that were all initially treated using a plaster cast for four months without success. These authors then recommended surgical treatment, using Herbert screws and bone grafts in 11 cases; bone grafts without fixation in six cases; bone grafts and Kirschner wires in two cases; and only a Herbert screw in one case. Thus, they showed that consolidation occurred with all the surgical treatment techniques among these children, and reported that that only the cases with bone grafts alone required a longer duration of immobilization. Therefore, these authors indicated surgical treatment as the best method for this type of lesion.

García-Mata $^{(3)}$ reported on four cases of pseudarthrosis in children under the age of 15 years who were treated surgically with bone grafts alone, and recommended this technique for cases in which reconstruction of the shape and length of the scaphoid was required. This author believed that, for children, there was no need for osteosynthesis because their potential for cure was greater than that of adults. Hamdi and Khelifi( ${ }^{(24)}$ and Maxted and Owen ${ }^{(25)}$ believed that using Kirschner wires on the bone graft was useful for achieving union and that this method was an important addition for the procedure. Waters and Stewart ${ }^{(14)}$ recommended the use of vascularized bone grafts in association with internal fixation for cases of avascular necrosis and pseudarthrosis of the scaphoid in immature skeletons. Southcott and Rosman ${ }^{(26)}$ indicated surgical treatment with a bone graft from the radius by means of an anterior route, while Caputo et $\mathrm{al}^{(27)}$ indicated the same technique, but via a dorsal route.

Mintzer and Waters ${ }^{(28)}$ and Mintzer et $\mathrm{al}^{(29)}$ reported the results from 13 cases of pseudarthrosis of the scaphoid in immature skeletons treated surgically. Four cases were treated using the Matti-Russe procedure $^{(30)}$ and nine cases with a bone graft plus a Herbert screw. All the cases evolved to bone union. They also reported that one small Herbert screw could be used in a small scaphoid without complications. Fugioka et $\mathrm{al}^{(31)}$ also reported that using a cannulated screw provided consolidation without interference in scaphoid growth. Most series have shown that it is safe to use compression screws in children over the age of 11 years, without risks of complications.

Masquijo and Willis ${ }^{(1)}$ reported on 23 cases of pseudarthrosis in immature skeletons, which were successfully treated by means of a surgical approach with a bone graft and fixation using a compression screw (Herbert or Acutrak ${ }^{\circledR}$ ) and indicated this procedure for cases of unstable pseudarthrosis in which the association of bone graft and internal fixation would combine the biological properties of the graft and the mechanical advantages of the compression screw. Jeon et $\mathrm{al}^{(8,9)}$ recommended percutaneous fixation with a Herbert screw for cases of stable pseudarthrosis with minimal bone reabsorption and without deformities. Slade et $\mathrm{al}^{(32)}$ reported that in selected cases of fibrous union or cases of non-union with minimal sclerosis that had the biological capability to achieve consolidation but lacked mechanical stability for cure to be attained, percutaneous fixation with a Herbert screw would be enough for consolidation. Finally, Toh et $\mathrm{al}^{(33)}$ reported on 46 cases of pseudarthrosis of the scaphoid in children, which was not considered to be a rare injury in their study, and they indicated surgical treatment with internal fixation as the best option.

\section{CLINICAL CASE}

A 14-year-old female patient sought our service because of pain in her left wrist, in the region of the anatomical snuffbox. She did not have any history of trauma. Anteroposterior and lateral radiographs on the wrist showed pseudarthrosis of the scaphoid (Figure 2). 
She underwent surgical treatment consisting of a vascularized bone graft and fixation using a Herbert screw, via a dorsal route. During outpatient follow-up, anteroposterior and lateral radiographs on her wrist showed consolidation of the scaphoid three months after the operation (Figure 3 ).

At a follow-up assessment of wrist function one year after the operation, the Green and O'Brien assessment system was used ${ }^{(34)}$. This classified the patient's functional ability as excellent, since the score presented was greater than 90 (Figure 4).

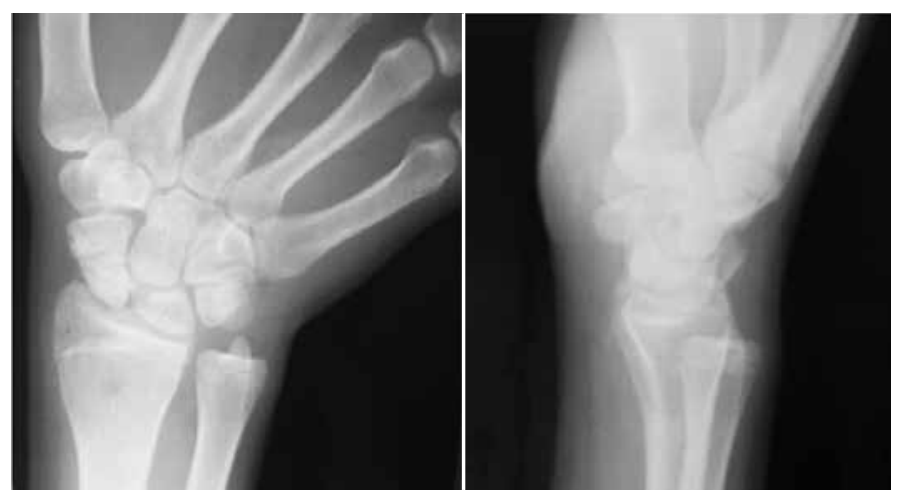

Figure 2 - Anteroposterior and lateral radiographs showing pseudarthrosis of the scaphoid in the middle third.

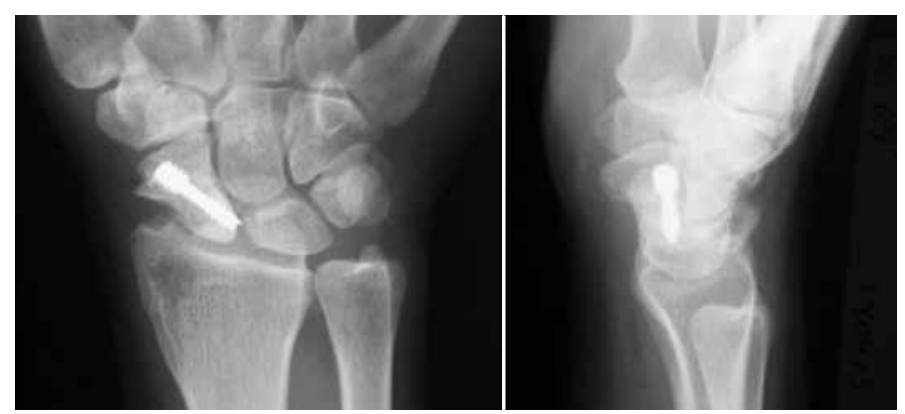

Figure 3 - Anteroposterior and lateral radiographs showing consolidation of the scaphoid.

\section{REFERENCES}

1. Masquijo JJ, Willis BR. Scaphoid nonunions in children and adolescents: surgical treatment with bone grafting and internal fixation. J Pediatr Orthop. 2010;30(2):119-24.

2. Elhassan BT, Shin AY. Scaphoid fracture in children. Hand Clin. 2006;22(1):31-41.

3. García-Mata S. Carpal scaphoid fracture nonunion in children. J Pediatr Orthop. 2002;22(4):448-51.

4. Hamdi MF, Khelifi A. Operative management of nonunion scaphoid fracture in children: a case report and literature review. Musculoskelet Surg. 2011;95(1):49-52.

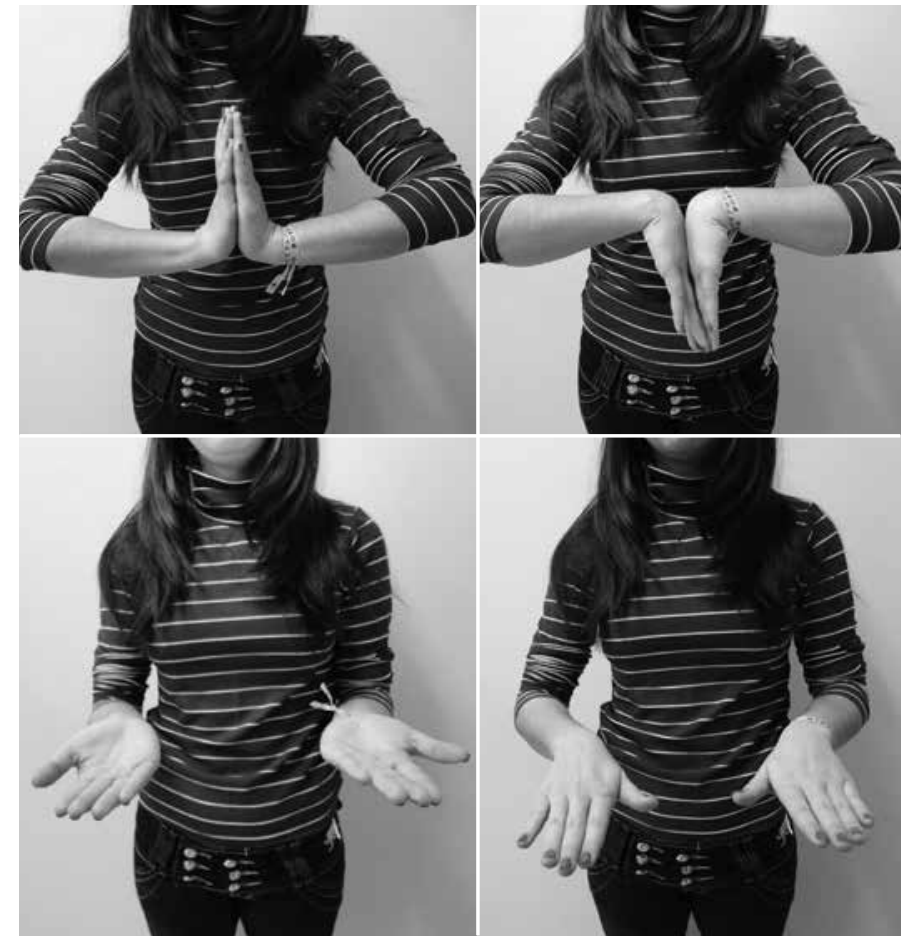

Figure 4 - Functional result.

\section{FINAL REMARKS}

Pseudarthrosis in skeletally immature patients is a rare event. However, appropriate attention needs to be given to children with wrist trauma, in order to avoid missing the diagnosis of fracture of the scaphoid and its correct treatment at the time of the initial trauma. There is still no standard treatment to follow. A variety of protocols have been used by a wide range of authors, who have all reported that the treatment used in the cases reported. Therefore, the treatment to be used depends on the characteristics of the pseudarthrosis and the surgeon's experience.
5. Evenski AJ, Adamczyk MJ, Steiner RP, Morscher MA, Riley PM. Clinically suspected scaphoid fractures in children. J Pediatr Orthop. 2009;29(4):352-5.

6. Gholson JJ, Bae DS, Zurakowski D, Waters PM. Scaphoid fractures in children and adolescents: contemporary injury patterns and factors influencing time to union. J Bone Joint Surg Am. 2011;93(13):1210-9.

7. Taleisnik J, Kelly PJ. The extraosseous and intraosseous blood supply of the scaphoid bone. J Bone Joint Surg Am. 1966;48(6):1125-37.

8. Jeon IH, Kochhar H, Micic ID, Oh SH, Kim SY, Kim PT. Clinical result of opera- 
tive treatment for scaphoid non-union in the skeletally immature: percutaneous versus open procedure. Hand Surg. 2008;13(1):11-6.

9. Jeon IH, Kochhar H, Lee BW, Kim SY, Kim PT. Percutaneous screw fixation for scaphoid nonunion in skeletally immature patients: a report of two cases. J Hand Surg Am. 2008;33(5):656-9.

10. Chloros GD, Themistocleous GS, Wiesler ER, Benetos IS, Efstathopoulos DG, Soucacos PN. Pediatric scaphoid nonunion. J Hand Surg Am. 2007;32(2):172-6.

11. Louis DS, Calhoun TP, Garn SM, Carroll RE, Burdi AR. Congenital bipartite scaphoid--fact or fiction? J Bone Joint Surg Am. 1976;58(8):1108-12.

12. Filan SL, Herbert TJ. Herbert screw fixation of scaphoid fractures. J Bone Joint Surg Br. 1996;78(4):519-29.

13. Clarke JV, Raamjug SD, Barnes SJ. Established scaphoid nonunion progressing to spontaneous union in a child. Injury. 2006;37(1): 171-2.

14. Waters PM, Stewart SL. Surgical treatment of nonunion and avascular necrosis of the proximal part of the scaphoid in adolescents. J Bone Joint Surg Am. 2002;84(6):915-20.

15. Osterman AL, Mikulics M. Scaphoid nonunion. Hand Clin. 1988;4(3):437-55.

16. Johnson KJ, Haigh SF, Symonds KE. MRI in the management of scaphoid fractures in skeletally immature patients. Pediatr Radiol. 2000;30(10):685-8.

17. Huckstadt T, Klitscher D, Weltzien A, Müller LP, Rommens PM, Schier F. Pediatric fractures of the carpal scaphoid: a retrospective clinical and radiological study. J Pediatr Orthop. 2007;27(4):447-50.

18. Weber DM, Fricker R, Ramseier LE. Conservative treatment of scaphoid nonunion in children and adolescents. J Bone Joint Surg Br. 2009;91(9):1213-6.

19. Duteille F, Dautel G. Non-union fractures of the scaphoid and carpal bones in children: surgical treatment. J Pediatr Orthop B. 2004;13(1):34-8.

20. Suzuki K, Herbert TJ. Spontaneous correction of dorsal intercalated segment instability deformity with scaphoid malunion in the skeletally immature. J Hand Surg Am. 1993;18(6):1012-5.
21. Fabre $\mathrm{O}$, De Boeck $\mathrm{H}$, Haentjens $\mathrm{P}$. Fractures and nonunions of the carpal scaphoid in children. Acta Orthop Belg. 2001;67(2):121-5.

22. Pick RY, Segal D. Carpal scaphoid fracture and non-union in an eight-year-old child. Report of a case. J Bone Joint Surg Am. 1983;65(8):1188-9.

23. Henderson $B$, Letts $M$. Operative management of pediatric scaphoid fracture nonunion. J Pediatr Orthop. 2003;23(3):402-6.

24. Hamdi MF, Khelifi A. Operative management of nonunion scaphoid fracture in children: a case report and literature review. Musculoskelet Surg. 2011;95(1):49-52.

25. Maxted MJ, Owen R. Two cases of non-union of carpal scaphoid fractures in children. Injury. 1982;13(5):441-3.

26. Southcott R, Rosman MA. Non-union of carpal scaphoid fractures in children. J Bone Joint Surg Br. 1977;59(1):20-3.

27. Caputo AE, Watson HK, Nissen C. Scaphoid nonunion in a child: a case report. J Hand Surg Am. 1995;20(2):243-5.

28. Mintzer CM, Waters PM. Surgical treatment of pediatric scaphoid fracture nonunions. J Pediatr Orthop. 1999;19(2):236-9.

29. Mintzer CM, Waters PM, Simmons BP. Nonunion of the scaphoid in children treated by Herbert screw fixation and bone grafting. A report of five cases. $J$ Bone Joint Surg Br. 1995;77(1):98-100.

30. Russe O. Fracture of the carpal navicular. Diagnosis, non-operative treatment, and operative treatment. J Bone Joint Surg Am. 1960;42:759-68.

31. Fujioka H, Tanaka J, Tomatsuri M. Scaphoid non-union after simultaneous fractures of the scaphoid and the capitate in a child: a case report. Hand Surg. 2006;11(3):151-2.

32. Slade JF 3rd, Geissler WB, Gutow AP, Merrell GA. Percutaneous internal fixation of selected scaphoid nonunions with an arthroscopically assisted dorsal approach. J Bone Joint Surg Am. 2003;85(Suppl 4):20-32.

33. Toh S, Miura H, Arai K, Yasumura M, Wada M, Tsubo K. Scaphoid fractures in children: problems and treatment. J Pediatr Orthop. 2003;23(2):216-21.

34. Green DP, O'Brien ET. Open reduction of carpal dislocations: indications and operative techniques. J Hand Surg Am. 1978;3(3):250-65. 